\title{
OS ASPECTOS ECONÔMICOS DA TARIFA MÍNIMA DE ÁGUA A PARTIR DA LEI $13.312 / 2016$
}

\section{THE ECONOMIC ASPECTS OF THE MINIMUM WATER TARIFF FROM THE LAW $13.312 / 2016$}

\author{
Oksandro Osdival Gonçalves ${ }^{1}$ \\ Viviane Taís Azoia²
}

\begin{abstract}
Resumo
Considerando o cenário atual brasileiro, o consumo mínimo de água e sua correspondente tarifa permanecem com limites estanques por várias décadas. A parcela da população que se enquadra nesta categoria sente-se desestimulada a fazer qualquer economia em seu consumo porque o usuário não recebe qualquer recompensa. Assim, o artigo tem por intuito analisar os aspectos econômicos que se relacionam à tarifação mínima de água e como esta relação pode (ou não) ser modificada com a introdução da Lei n.13.312/2016. Sob a perspectiva da análise econômica do direito, os free riders podem, com a referida lei, ser combatidos, porém, permanece (ou se intensifica) o número de unidades consumidoras com usuários não oportunistas não contemplados por qualquer recompensa quando cooperam para o uso racional deste recurso hídrico. Em face disso, a imposição de tarifa mínima no Brasil, variável de acordo com cada Estado da Federação, merece e demanda ser revisitada por novos estudos técnico-científicos capazes de viabilizar econômica e racionalmente o fornecimento de água potável, fazendo deste um sistema mais eficiente.
\end{abstract}

Palavras-chave: Tarifa Mínima de Água; Lei do Hidrômetro Individual; Análise Econômica do Direito; Políticas Públicas; Desenvolvimento.

\begin{abstract}
Considering the current Brazilian scenario, the minimum water consumption and its corresponding tariff remain with watertight limits for several decades. The portion of the population which fits in this category feels discouraged to make any savings in its consumption, since for that rational action, the user does not receive any reward. Therefore, this article aims to analyze the economic aspects related to the minimum water charging and how this relationship can (or not) be modified with the introduction of the Law 13.312 / 2016. From the perspective of the economic analysis of law, free riders can, with this law, be combated, however, the number of consumer units with non-opportunistic users which does not receive any reward when they cooperate for rational use of this hydric resource remains (or intensifies). In view of that, the imposition of a minimum tariff in Brazil, which varies according to each state, deserves and demands to be revisited by new technical-scientific studies capable of economically and rationally providing potable water supply, making it a more efficient system.
\end{abstract}

\footnotetext{
${ }^{1}$ Doutor em Direito Comercial pela Pontifícia Universidade Católica de São Paulo. Professor do Programa de Pós-Graduação em Direito (Mestrado/Doutorado) da Pontifícia Universidade Católica do Paraná. Professor de Direito Comercial da Escola de Direito da Pontifícia Universidade Católica do Paraná. Professor de Direito Empresarial do Curso de Especialização em Direito Civil e Empresarial da Pontifícia Universidade Católica do Paraná. Membro do Conselho Editorial da Editora Fórum. Coordenador da Revista de Direito Empresarial. Bolsista CAPES. E-mail: oksandro@cgaadv.com.br

${ }^{2}$ Mestranda em Direito Econômico e Socioambiental pela Pontifícia Universidade Católica do Paraná. Email: vivianeazoia@gmail.com
} 
Keywords: Minimum Water Tariff; Individual Hydrometer Law; Economic Analysis of Law; Public Politics; Development.

\section{INTRODUÇÃO}

Atualmente as preocupações ambientais demandam cada dia mais objetividade e precisão, pois a degradação ocorre a uma velocidade exponencial, motivo pelo qual o papel do Direito Econômico, neste texto compreendido como o direito apropriado para tratar da intervenção do Estado na economia, é de suma importância.

Consequentemente, a busca por novos mecanismos que auxiliem na eficiência ambiental na tratativa de recursos naturais escassos é estratégica, pois a adoção de decisões economicamente racionais pode conduzir a uma desaceleração na degradação em quantidade e qualidade dos recursos disponíveis e acessíveis.

A tarifação mínima de água hoje representa uma categoria de consumo constituída por expressiva parcela da população que se encontra em uma espécie de "limbo", pois não são estimulados de nenhuma maneira a economizar no consumo, uma vez que o valor cobrado não se altera dentro daquela faixa limite, logo, consumindo quantidades diferentes dentro da faixa limite (de $10 \mathrm{~m}^{3}$ no estado do Paraná, por exemplo), arcam todos com o mesmo valor.

Com a Lei n. 13.312/2016, este cenário de desestímulo tende a se intensificar, pois aumentaram o número de unidades que passarão a ter hidrômetro individual e que se enquadrarão na categoria de consumo mínimo, anteriormente participantes em sua grande maioria, de rateio igualitário condominial.

O artigo objetiva analisar os aspectos econômicos relacionados à tarifa mínima de água e o formato que assumirão com a entrada em vigor da Lei n. 13.312/2016. Para tanto, serão abordadas, na primeira parte, as legislações que permeiam a tarifa mínima de água e a legalidade de sua cobrança no sistema jurídico brasileiro, ainda que aos estados seja dada a liberdade em fixar seus limites, bem como os valores cobrados. Essa abordagem não deixa de mencionar tal interpretação legal frente à escassez de água potável que recai sobre todo o planeta, o que torna evidente a necessidade de se buscar mecanismos que efetivem o desenvolvimento sustentável.

A segunda parte é dedicada a enfrentar como a tarifa mínima de água tem sido adotada pelos diversos estados brasileiros e os valores cobrados pelo uso, bem como demonstra a 
possibilidade de existência de faixas de consumo mínimo variáveis à adotada pela maioria dos estados que é de $10 \mathrm{~m}^{3}$, comparando-as, quando possível, ao estado do Paraná especialmente.

Por fim, no último tópico, expõe-se a tarifação mínima de água à Lei do hidrômetro individual (Lei n. 13.312/2016), a qual será, sob a ótica da Análise Econômica do Direito, um novo instrumental para o enfrentamento de problemas jurídicos, no intuito de apresentar não apenas justificativas ambientais à referida lei, mas também aspectos racionais de escolha a fim de se alcançar maior eficiência na proposta de soluções ao problema ambiental, especialmente no que tange à escassez dos recursos hídricos.

\section{A LEGALIDADE DA TARIFA MÍNIMA E A LEI N. 13.312/2016 FRENTE À ESCASSEZ DA ÁGUA}

A utilização, importância e disponibilidade da água no Brasil não foi, por um longo período, uma preocupação de destaque. Porém, a situação se alterou e tornou-se uma inquietação real das famílias, notícia na mídia e uma problemática a ser resolvida (com urgência) pelo Estado, por sua responsabilidade em disponibilizar água em quantidade e qualidade mínimas aos indivíduos.

Esse comprometimento dos recursos naturais se deve, em grande parte, ao esgotamento e ao aumento populacional que levaram a água a tornar-se cada vez mais um recurso disputado. Agravando a situação, somam-se os sucessivos desastres ecológicos que acabam por contaminar ou comprometer a qualidade e a quantidade disponível deste recurso (FREITAS, 2002, p. 18).

Para Betti Jr. (2011, p. 309), uma grande influência na degradação ambiental provém das intensas relações de produção e consumo e a consciência da sociedade atual sobre esta problemática decorre justamente da intensa difusão de informações a que está exposta. Essa consciência, por sua vez, demanda um modelo de desenvolvimento ${ }^{3}$ sustentável que seja capaz de lidar com o problema da escassez, garantindo suprimento de água suficiente para a presente e futuras gerações (princípio da solidariedade intergeracional).

O acompanhamento da tendência em preocupar-se com este recurso pode ser observado na Constituição Federal de 1988 que, em seu artigo 26, inciso I, torna bens dos estados "as águas superficiais ou subterrâneas, fluentes, emergentes e em depósito,

\footnotetext{
3 Observa-se aqui o emprego da palavra "desenvolvimento" com um sentido que vai além de "crescimento econômico", atingindo um conjunto de processos sociais capazes de maximizar a possibilidade de exercer efetivamente as liberdades substanciais. Sobre o assunto, ver: SEN, Amartya Kumar. Desenvolvimento como liberdade. São Paulo: Companhia das Letras, 2000.
} 
ressalvadas, neste caso, na forma da lei, as decorrentes de obras da União" (BRASIL, 1988). Com isso, acabam-se as águas particulares ou comuns, previstas no Código Civil de 1916 e no Código das Águas. A implementação desta previsão constitucional viria com a Lei n. 9.433/1997, que em seu artigo 1ํ, inciso I, estabelece que "a água é um bem de domínio público" (BRASIL, 1997).

De início, necessário se faz diferenciar "tarifa" de "taxa" para que não sejam erroneamente empregados os termos. Enquanto a taxa se relaciona a um valor pago pelo efetivo ou potencial utilização de um serviço público uti singuli e específico ou mediante o qual se remunera o exercício de polícia administrativa, a tarifa representa a simples unidade base para o cálculo do valor a ser pago pelo usuário de um serviço público (BLANCHET, 2015, p. 144), ou seja, "tarifa envolve contraprestação, retribuição, de natureza contratual, daí o caráter facultativo do preço público, a liberdade de escolha do usuário. Taxa é espécie do gênero tributo e receita fiscal [...] a taxa é exigível por força de lei" (BLANCHET, 2006, p. 64). Para Blanchet (2014, p. 09), a tarifa representa uma contraprestação decorrente de um contrato enquanto a taxa "deriva de uma imposição legal, é devida pela prestação efetiva ou pela simples disponibilização de serviço público de caráter específico e divisível, consoante estatui a Constituição da República em seu art. 145, II".

A tarifação mínima de água e a tendência na adoção do consumo mínimo em $10 \mathrm{~m}^{3}$ não são recentes e sua legalidade é pacífica e amparada por sucessivas legislações brasileiras. Prevista legalmente pela já revogada Lei n. 6.528/1978 (art. 4ํ) que dispunha sobre as tarifas dos serviços públicos de saneamento básico e seu Decreto regulamentador n. 82.587/1978 (arts. 11, §20 e 12), também já revogado pelo Decreto de 05 de setembro de 1991, a tarifação mínima de água demonstra uma tendência de fixação no valor mínimo de consumo de $10 \mathrm{~m}^{3}$ mensais.

Na legislação vigente, a Lei n.o 6.528/1978 e seu Decreto regulamentador n.응 82.587/1978 foram revogados e substituídos pela Lei $\mathrm{n}$. - $11.445 / 2007$, elaborada a fim de estabelecer as diretrizes nacionais para o saneamento básico, regulamentada pelo Decreto n.․․ 7.217/2010. Na Lei n. 11.445/2007 (BRASIL, 2007), o artigo 29, §1으, inciso IV, manifesta a

\footnotetext{
${ }^{4}$ Art. 29. Os serviços públicos de saneamento básico terão a sustentabilidade econômico-financeira assegurada, sempre que possível, mediante remuneração pela cobrança dos serviços:

$\S 1$ O Observado o disposto nos incisos I a III do caput deste artigo, a instituição das tarifas, preços públicos e taxas para os serviços de saneamento básico observará as seguintes diretrizes:

IV - inibição do consumo supérfluo e do desperdício de recursos;
} 
necessária busca pela eficiência e o artigo 30 , inciso $\mathrm{I}^{5}$, a legalidade em distribuir os usuários em faixas de consumo.

Os artigos 29 e 30 acima mencionados, corroborados fielmente pelos artigos 46 e 47 do Decreto $n .0$ 7.217/2010 (BRASIL, 2010a) que regulamenta a Lei $n .0$ 11.445/2007, impõem especificamente que os serviços públicos de saneamento básico, constituído pelo serviço de abastecimento de água, inclusive, serão mantidos econômico e financeiramente através da cobrança, preferencialmente, de uma tarifa ou outro preço público, sendo permitido o estabelecimento de categorias de usuários, distribuídas em faixas ou quantidades crescentes de utilização ou de consumo.

Os incisos III e IV do artigo 30 evidenciam ainda uma clara preocupação em garantir objetivos sociais, principalmente o fornecimento de quantidade mínima aos usuários de menor renda, bem como a efetivação de um custo mínimo capaz de manter o serviço, dentro de um padrão de quantidade e qualidade adequado. Neste ponto, pode-se citar a justificativa amplamente utilizada e que ainda será explorada neste estudo, acerca do financiamento do mínimo existencial às classes menos favorecidas por meio do subsídio gerado na tarifação mínima de água, ou, como tecnicamente se conhece, o "volume de água faturado não consumido" que se converte em subsídio da "tarifa social".

Além disso, a legalidade da tarifação mínima de água é reforçada pela Lei n. 8.987/1995 que dispõe sobre o regime de concessão e permissão da prestação de serviços públicos, e que em seu artigo $13^{6}$ (BRASIL, 1995) estabelece ser possível a diferenciação na cobrança em função de segmentos de usuários.

É importante observar que, com tais previsões legais, é pacífica e lícita a cobrança de tarifa de água no valor do consumo mínimo, ainda que não se tenha consumido efetivamente o volume compreendido dentro da margem de consumo máximo.

A questão também abre a discussão em torno da modicidade das tarifas neste ponto, que segundo Blanchet (2011, p. 69):

Módica é, pois, a tarifa que propicia ao concessionário condições para prestar serviço adequado e, ao mesmo tempo, lhe possibilita a justa remuneração dos recursos comprometidos na execução do objeto da concessão. Sem esta garantia, o Estado jamais contaria com a colaboração honesta da iniciativa privada. O particular, afinal, não tem

\footnotetext{
${ }^{5}$ Art. 30. Observado o disposto no art. 29 desta Lei, a estrutura de remuneração e cobrança dos serviços públicos de saneamento básico poderá levar em consideração os seguintes fatores:

I - categorias de usuários, distribuídas por faixas ou quantidades crescentes de utilização ou de consumo;

${ }^{6}$ Art. 13. As tarifas poderão ser diferenciadas em função das características técnicas e dos custos específicos provenientes do atendimento aos distintos segmentos de usuários.
} 
obrigação de custear o atendimento de necessidades públicas. Este é um dever do Estado.

Porém, Mello (2015, p. 741), ao tratar da licitação nas concessões, afirma que:

[...] o serviço público, por definição, existe para satisfazer necessidades públicas e não para proporcionar ganhos ao Estado. Aliás, esta mesma Lei 8.987, em seu art. 6ํㅡ, após considerar que toda concessão ou permissão pressupõe serviço adequado, no $\$ 1$ o dele, esclarece que serviço adequado é o que satisfaz, entre outras condições, a "modicidade das tarifas", a qual, de resto, é um princípio universal do serviço público. Assim, serviço público desenganadamente não é instrumento de captação de recursos para o Poder Público. Este não é um capitalista a mais no sistema. Os recursos de que necessita para cumprir suas missões (inclusive a de prestar serviço público) são captáveis pela via tributária ou pela emissão de títulos. Atribuir peso importante à maior oferta de candidato à prestação de serviço público é contribuir para que este ofereça tarifa maior, embutindo nela o custo em que terá de arcar com sua oferta, o que é a antítese do desejável.

Neste contexto, a tarifa mínima representa a concretização do princípio da função social no serviço de fornecimento de água no momento que dá acesso a um consumo expressivo de volume de água a preços módicos a uma categoria de usuários considerados mais pobres. Ao mesmo tempo, essa tarifação mínima torna possível a manutenção do equilíbrio econômico-financeiro do sistema de acesso ao serviço público de abastecimento de água, uma vez que o custo deste subsídio se dilui em razão da cobrança da tarifa mínima de água (BRASIL, 2010b), equilibrando a equação econômico-financeira necessária ao suprimento dessa importante necessidade.

Consequentemente, vê-se a tarifação mínima, normalmente fixada em $10 \mathrm{~m}^{3}$ de água em grande parte dos estados brasileiros, como um consumo de água efetivo inferior ao estipulado como necessário para manter o funcionamento do sistema de fornecimento e abastecimento de água, devendo, portanto, ser sobretarifado, ainda que o volume consumido não corresponda, necessariamente, à tarifa cobrada.

Evidente que, em uma relação jurídica estabelecida entre concessionária e condomínio (usuário do serviço público de fornecimento de água) apenas (e não com cada um dos imóveis constituintes do condomínio), ao desprezar o volume de água efetivamente consumido e registrado, enriquece-se indevidamente a concessionária ao se cobrar além do necessário para cobrir os custos do serviço prestado. 
Por isso, a Lei n. $13.312^{7}$, de 12 de julho de 2016 (BRASIL, 2016a), destinou-se a alterar pontualmente o artigo 29 da Lei n.o 11.445/2007, obrigando as novas edificações condominiais a utilizarem hidrômetros individuais para medição do consumo hídrico em prol da sustentabilidade ambiental. A entrada em vigor da Lei do hidrômetro individual se dará após cinco anos de sua publicação oficial.

O Projeto de Lei originário (n. 444/2011), além das justificativas relacionadas à competência em regular a matéria que não são objeto deste estudo, trouxe ainda como justificativas materiais a sustentabilidade no consumo e uma suposta preocupação com os consumidores:

No esforço que se impõe ao Estado e à sociedade relativamente à adoção de padrões sustentáveis no consumo de recursos naturais, sobreleva-se a importância da economia de água tratada. Nessa imensa tarefa, torna-se especialmente necessário incentivar os consumidores no sentido de adotarem comportamentos mais comedidos no que se refere à utilização de recursos hídricos.

Nos condomínios urbanos, embora a medição do consumo de outros serviços públicos, como os de fornecimento de energia elétrica e telefonia, ocorra de forma individualizada, no caso da água, essa conduta deixa de prevalecer. De forma injustificada, o consumo hídrico é comumente incluído nas despesas condominiais, partilhadas indistintamente na proporção das respectivas frações ideais. Inadequado e injusto, esse modelo tende a prejudicar os consumidores mais comedidos e favorecer os mais perdulários, circunstância que enseja elevados desperdícios desse insumo vital, que enfrenta crescente risco de escassez.

A presente iniciativa tem, assim, o sentido de promover o consumo responsável da água. De acordo com estudos especializados, o sistema de medição individual, adotado em países como a França, por exemplo, tem obtido reduções da ordem de $25 \%$ no padrão de consumo hídrico. 0 Brasil possui a maior reserva de água doce do mundo e é um grande desperdiçador de água potável (BRASIL, 2011, p. 1-2).

O parecer favorável da Comissão de Desenvolvimento Regional e Turismo ao Projeto de Lei acima referido desperta interesse, pois, além de entender "louvável a iniciativa consubstanciada nos projetos em análise, pois permite que exista uma correlação precisa entre a cobrança e o consumo dos serviços de água e esgoto em cada unidade imobiliária, o que contribui para a diminuição do desperdício" (BRASIL, 2012), acrescentou um aspecto econômico

\footnotetext{
${ }^{7}$ Art. 10 Esta Lei torna obrigatória a medição individualizada do consumo hídrico nas novas edificações condominiais.

Art. 2 O 0 art. 29 da Lei no 11.445, de 5 de janeiro de 2007, passa a vigorar acrescido do seguinte $\S 3$ :

"Art. 29. §3ㅇ As novas edificações condominiais adotarão padrões de sustentabilidade ambiental que incluam, entre outros procedimentos, a medição individualizada do consumo hídrico por unidade imobiliária."

Art. 3ํ Esta Lei entra em vigor após decorridos cinco anos de sua publicação oficial.
} 
à avaliação, mas sob a perspectiva do consumidor, pois a alocação do custo desse bem não foi analisada sob a ótica ambiental que é superior àquela:

O benefício para os moradores é o fim das distorções na conta de água. Na ausência de equipamento de medição individual, uma pessoa que more sozinha desembolsa a mesma quantia de uma família com muitos integrantes. Sob o prisma econômico, a medida coíbe o chamado comportamento de "carona", que ocorre quando um indivíduo usufrui de um bem comum em medida maior do que a de sua contribuição para o custeio desse mesmo bem. Quando a água do condomínio não é cobrada conforme o consumo de cada unidade, é grande o incentivo ao desperdício, já que um consumo maior (banhos demorados, torneiras abertas, tubulações sem manutenção, etc.) não corresponde a um aumento equivalente na tarifa cobrada. A medição e a cobrança individualizadas pelo consumo, além de criarem um incentivo para se economizar água, promovem uma adequada alocação do custo desse bem (BRASIL, 2012, p. 3).

Pelas causas expostas, e apesar do paradoxo da exposição de motivos, a escassez de água potável em quantidade e qualidade suficientes à população é um problema de grande relevância no cenário global e que atualmente, as preocupações têm se tornando mais objetivas e demandado medidas mais efetivas a fim de conduzir a um consumo mais racional.

Por este motivo, essa escassez do recurso tem sido observada e utilizada como argumentação legislativa no cenário brasileiro em diversas frentes a fim de conduzir a sociedade brasileira a um consumo mais racional de água. Basta analisar se estas medidas são racionalmente efetivas na proteção da quantidade e qualidade da água, como recurso fundamental à sobrevivência humana.

Além disso, é importante frisar que os discursos justificativos e legislativos no sentido de incentivarem a economia de água omitem uma categoria expressiva da população brasileira no que tange o consumo de água potável que é aquela enquadrada dentro da categoria de consumo mínimo.

\section{O CENÁRIO DA TARIFA MÍNIMA DE ÁGUA NO BRASIL E NO ESTADO DO PARANÁ}

A Lei n. 9.433/1997 destinada a regulamentar o inciso XIX do art. 21, da Constituição Federal $^{8}$ (BRASIL, 1988) que institui a Política Nacional de Recursos Hídricos, está assentada basicamente nos fundamentos de que a água é um bem de domínio público e um recurso natural limitado, dotado de valor econômico. Com base em tais dispositivos pode-se depreender que o usuário deve pagar pela utilização da água por ser esta um bem de domínio

\footnotetext{
${ }^{8}$ Art. 21. Compete à União: XIX - instituir sistema nacional de gerenciamento de recursos hídricos e definir critérios de outorga de direitos de seu uso;
} 
público, dotada de valor econômico, uma vez que se trata de um recurso natural escasso. Mas, como afirma Granziera (2006, p. 209), hoje se paga pela prestação de serviços de captação, tratamento e fornecimento de água, e não pelo recurso em si.

O estudo da função demanda por serviços de saneamento e estudo da tarifação do consumo residencial do Instituto de Pesquisa Econômica Aplicada (Ipea), de maio de 1996, já identificava que a cobrança por serviços de água e esgoto normalmente se faz por meio de uma "estrutura tarifária em blocos de consumo" (ETB) e que esta estrutura tem por característica definir preços, normalmente crescentes, previamente definidos pela empresa de saneamento:

Uma característica básica da ETB é que, na primeira faixa de consumo, todos os usuários pagam pelo consumo máximo, quer utilizem ou não aquela quantidade. Isso significa, em outras palavras, que existe uma decisão inicial do consumidor em participar ou não do serviço de água e depois decisões marginais com relação à passagem para blocos de consumo (BRASIL, 1996, p. 14).

O estudo ainda explica que, sob a ótica da microeconomia, considera-se a hipótese de que os consumidores agem de forma racional, estando restritos aos seus orçamentos disponíveis e observando-os, têm suas preferências relacionadas às quantidades dos possíveis bens que podem adquirir, assim como é o caso da água, maximizando as suas funções de utilidade (BRASIL, 1996, p. 14).

Considerando as estruturas tarifárias vigentes à época e as estruturas alternativas, especificamente no que diz respeito ao valor mínimo da conta de água (que para a SaneparParaná, à época do estudo, já era de $10 \mathrm{~m}^{3}$ por mês), é possível observar um consenso entre grande parte das empresas de saneamento no Brasil em adotarem estruturas tarifárias residenciais com um valor mínimo mensal, representando esta conta mínima a "cobrança obrigatória de uma quantidade estabelecida de unidades de consumo residencial de água, mesmo se de fato o usuário do serviço consumir uma quantidade inferior à quantidade cobrada" (BRASIL, 1996, p. 35).

Criticamente, o estabelecimento de um valor mínimo da conta de água residencial incorre, em pelo menos, dois problemas relevantes. O primeiro deles pode ser observado no impacto financeiro ao qual a tarifa mínima conduz que recai pesadamente sobre os usuários que consomem uma menor quantidade de água, mas que, ainda assim, se enquadram nesta categoria. Como é possível identificar relação entre a renda do usuário e o seu consumo de água, observando toda a parcela da população que se enquadra na tarifa mínima de consumo, aqueles de menor renda são mais adversamente afetados pela cobrança mínima obrigatória. 
Assim, dentro desta categoria, podem-se observar distorções do próprio objetivo distributivo da política de preços praticada pela empresa de saneamento (BRASIL, 1996, p. 35).

A segunda dificuldade é produto da tarifa mínima obrigatória de água e está relacionada à geração da receita da empresa de saneamento:

O segundo problema que a conta mínima obrigatória causa é que o sinal dado pelo preço aos consumidores é baixo. A receita extra cobrada dos usuários que consomem menos que a quantidade limite (por exemplo, 10 $\mathrm{m}^{3}$ por mês) permite que a empresa de saneamento cobre preços mais baixos aos demais consumidores. Se a exigência de pagar um valor mínimo obrigatório fosse removida, as receitas decresceriam e, então, as tarifas residenciais teriam que aumentar para ser mantido o mesmo nível de receita anterior. Este aumento nas tarifas tenderia a diminuir a quantidade demandada de água (BRASIL, 1996, p. 35-36).

Com a listagem destes dois efeitos negativos do estabelecimento de tarifa mínima obrigatória, vê-se que esta categoria de diferenciação afeta adversamente o objetivo distributivo e, ainda pior, desestimula financeiramente o usuário residencial a diminuir o seu consumo de água, uma vez que, economizar não gera em contrapartida qualquer redução na conta.

Considerando que qualquer usuário pode ser estimulado ou desestimulado a consumir determinado bem/produto, esta categoria de consumo fica desencorajada a ir no sentido econômico-ambiental desejável para a atual sociedade. Este mesmo resultado se ampliará no momento em que a Lei n. 13.312/2016 entrar em vigor, aumentando expressivamente o número de unidades consumidoras que se enquadrarão nesta categoria.

Isso se comprova, pois, segundo o Instituto Brasileiro de Geografia e Estatística (IBGE, 2012), o número médio de pessoas por família residente em domicílio particular em 2012, no estado do Paraná, por exemplo, foi de 2,9 pessoas. Deste número, 73,4\% são economicamente ativas e os outros $26,6 \%$ são membros não economicamente ativos. Ou seja, significa dizer que, dos 2,9 membros de uma família, 2,12 deles são economicamente ativos, desenvolvendo trabalho remunerado. Embora na atualidade parcela da população realize trabalho remunerado em sua própria residência, ainda prevalecem aqueles que realizam trabalhos em outro lugar. Estes números reforçam a tese de que com a inserção da Lei n. 13.312/2016, haverá um aumento expressivo de unidades enquadradas na categoria de consumo mínimo.

No caso específico do estado do Paraná, o Decreto Estadual n. 3.576, de 29 de fevereiro de 2016, regula a cobrança das tarifas de abastecimento de água tratada e esgotamento sanitário e autoriza o reajuste das tarifas pela Companhia de Saneamento do Paraná (Sanepar). Para este estudo interessa apontar apenas os valores das tarifas de água de consumo 
residencial, uma vez que é possível relaciona-la à Lei n. 13.312/2016 (para o consumo de até $10 \mathrm{~m}^{3}$ ): tarifa social para todas as localidades operadas $-R \$ 8,86$ (oito reais e oitenta e seis centavos), o que representa $26,26 \%$ do valor da tarifa residencial normal; tarifa normal residencial para todas as localidades operadas - $R \$ 33,74$ (trinta e três reais e setenta e quatro centavos) (PARANÁ, 2016).

Assim, daqueles que se enquadram nos requisitos para obter a tarifa social ${ }^{9}$ são cobrados valores que representam aproximadamente $75 \%$ a menos que os valores cobrados dos indivíduos que demandam a mesma quantidade de água para consumo residencial, mas que não se enquadram nos requisitos estabelecidos.

Porém, deve-se ressaltar que a tarifa social é uma espécie de subsídio, ou seja, "é um instrumento de política econômica que oferece recursos a um grupo, produtores ou consumidores, de modo a alterar o equilíbrio de mercado natural, com intuito de oferecer um bem maior à sociedade" (BRASIL, 2016b, p. 73) e os serviços de abastecimento de água e esgotamento sanitário, por se tratar de um assunto de saúde pública, possuem características que justificam a adoção deste tipo de política, além de demandarem uma prestação de qualidade e eficiência.

Há aqui uma dupla exclusão no que diz respeito ao desestímulo em economizar: os indivíduos que se encontram dentro da categoria de consumo de até $10 \mathrm{~m}^{3}$ residenciais, mas que não se enquadram na tarifa social, não recebem qualquer benefício financeiro ao tomar em seu cotidiano práticas ambientalmente mais conscientes e racionais. Neste cenário de desincentivo, a família que consome $9 \mathrm{~m}^{3}$, por exemplo, não vê qualquer "ganho" financeiro ao racionar seus banhos e o número de lavagens de roupa e passarem a consumir $6 \mathrm{~m}^{3}$. Com isso, haveria uma clara prática racionalmente ambiental, mas sem incentivo financeiro, o indivíduo/família sente-se desestimulada a economizar.

Ao longo deste estudo, diversas vezes foi usado o valor de $10 \mathrm{~m}^{3}$ de tarifação mínima para consumo residencial de água, mas faz-se necessário esclarecer que esta não é uma limitação fixa para todos os estados brasileiros. Dessa forma, a partir da utilização do Diagnóstico dos Serviços de Água e Esgotos de 2014 (publicado em fevereiro de 2016), é possível constatar variações neste sentido, bem como na demanda por água de abastecimento,

\footnotetext{
${ }^{9}$ A implantação da tarifa social objetiva "garantir a equidade e o acesso universal aos serviços de saneamento, de forma a proteger os usuários sem condições financeiras de uma desconexão por incapacidade de arcar com os custos das tarifas" (BRASIL, 2016b, p. 77).
} 
tarifas cobradas, funcionamento das companhias de saneamento, etc., dando enfoque sempre que possível, ao estado do Paraná.

$\mathrm{Na}$ denominada "tarifa mínima" independe a quantidade de água consumida, compreendendo um valor que corresponde a um mínimo a ser faturado, ainda que o consumo do usuário seja inferior a esse valor pré-estabelecido. Desta forma, "a tarifa mínima deve atender à viabilidade econômico-financeira dos prestadores de serviços, sempre sujeito a elevados gastos para manter a estrutura necessária à prestação do serviço, garantindo a disponibilidade do serviço" (BRASIL, 2016b, p. 73).

Ao se analisar nacionalmente (incluindo prestadores de abrangência regional, microrregional e local, segundo o Diagnóstico, que variam de acordo com a área de abrangência em que a empresa concessionária atua), as companhias de saneamento apresentam inúmeros valores como delimitador de tarifa mínima, além do já mencionado $10 \mathrm{~m}^{3}$. Podem ser encontrados valores tais como: $1 \mathrm{~m}^{3}$ (São João do Arraial/PI; Oliveira/MG e Alto Feliz/RS), $5 \mathrm{~m}^{3}$ (em companhias de abrangência local e na Copanor/MG), $6 \mathrm{~m}^{3}$ (Campo Belo/MG), $7 \mathrm{~m}^{3}$ (Getulina/SP), $15 \mathrm{~m}^{3}$ (Itapemirim/ES), 18m³ (Depasa-AC), 20m³ (Baião/PA; Viana/MA e Itapura/MG), 90m³ (Garça/SP) e 100m³ (Capitão Andrade/MG e Vila Rica/MT) (BRASIL, 2016b, p. 74-75). Ainda com tais variações, constata-se no estudo uma preponderância pela tarifa mínima de $10 \mathrm{~m}^{3}$, como também é o caso do estado do Paraná.

Por sua vez, realizando um comparativo com outras companhias de mesma tarifa mínima de $10 \mathrm{~m}^{3}$, o estado do Paraná (Sanepar) cobrava por ela, em 2014, R\$25,10 (vinte e cinco reais e dez centavos) por mês, enquanto a Casan (Santa Catarina) apresentava valor de R\$ 32,10 (trinta e dois reais e dez centavos); a Sanesul (Mato Grosso do Sul) R\$28,50 (vinte e oito reais e cinquenta centavos); a Sabesp (São Paulo) R\$ 17,90 (dezessete reais e noventa centavos) e a Simae (Capinzal-SC) R\$ 8,60 (oito reais e sessenta centavos). Nota-se, evidentemente, que, além de uma grande variação na fixação de consumo para a tarifa mínima, a variação no valor cobrado por ela também é expressiva por todo o território nacional (BRASIL, 2016b, p. 74-75).

O Sistema Nacional de Informações sobre Saneamento (SNIS), que produz os índices de atendimento dos serviços de abastecimento de água e esgotamento sanitário, divulgou neste mesmo estudo que o índice de atendimento com rede (água), para a região Sul do país, é de $88,2 \%$ no atendimento total e de $97,3 \%$ no atendimento urbano. Assim, a região Sul é a que apresenta o maior índice de atendimento urbano dentre todas as regiões do país (a média brasileira para este índice é de 93,2\%) (BRASIL, 2016b, p. 24). 
No que diz respeito ao fornecimento de água, o estado do Paraná encontra-se em situação levemente privilegiada quando comparado aos estados das outras regiões, embora grande parte deles apresentem também índices médios de atendimento urbano por rede de água acima de 90\%, como é o caso dos estados do Paraná (destaque para os dados de que 100\% dos municípios paranaenses enquadram-se neste índice) (BRASIL, 2016b, p. 28), Minas Gerais, Roraima, Mato Grosso do Sul, São Paulo, Paraíba, Mato Grosso, Santa Catarina, Piauí, Tocantins, Rio Grande do Norte, Goiás, Bahia, Rio Grande do Sul, Sergipe, Alagoas, Espírito Santo e Rio de Janeiro, além do Distrito Federal (BRASIL, 2016b, p. 26).

Acerca do consumo médio per capita de água que representa "a média diária, por indivíduo, dos volumes utilizados para satisfazer os consumos domésticos, comercial, público e industrial" (BRASIL, 2016b, p. 32), ele permite o desenvolvimento de projeções de demanda que serão essenciais no dimensionamento dos sistemas de abastecimento de água e esgoto, além do próprio controle operacional. O estado do Paraná se destaca no que tange um consumo médio que pode ser considerado racional em relação a outros estados e até mesmo à média brasileira.

O índice paranaense, que é medido em litros/habitante.dia, apresentou valor médio para os últimos três anos de 145,1 l/hab.dia e para o ano de 2014 houve uma redução, passando a 144,9 I/hab.dia. Dentre os estados da região Sul, o Paraná foi o estado com a menor média, sendo a média da região para os últimos três anos 150,9 I/hab.dia e para o ano de 2014, 153,6 l/hab.dia. Ainda assim, todos estes valores de consumo estão abaixo das médias nacionais que foram de 165,3 I/hab.dia para os últimos três anos e de 162,0 I/hab.dia para o ano de 2014 (BRASIL, 2016b, p. 32-33).

Considerando os índices de todos os estados brasileiros e do Distrito Federal, a variação entre a média dos três últimos anos e para o ano de 2014 foi positiva, ou seja, houve um aumento no consumo, em onze estados. Nos outros quinze estados e no Distrito Federal houve uma redução no consumo. Isso demonstra uma conscientização (aliada, é claro, a outros fatores influenciadores como temperatura ambiente, valor cobrado por metro cúbico, índice pluviométrico, renda mensal, idade, sexo, número de habitantes, disponibilidade de fornecimento, ampliação nas redes, etc.) em economizar um recurso escasso, mas também é flagrante que em onze estados ainda são necessárias medidas efetivas de incentivo que reduzam este consumo.

Relacionando as despesas totais médias e as tarifas médias cobradas pelos prestadores de serviços participantes do SNIS no Brasil para o ano de 2014 (composto por prestadores de 
abrangência regional, microrregional e local, segundo o Diagnóstico), dá-se ênfase à região Sul que é a terceira com a maior despesa média para o ano de $2014\left(R \$ 3,18 / \mathrm{m}^{3}\right)$, enquanto o estado do Paraná tem a média de $R \$ 2,52 / \mathrm{m}^{3}$ e o Brasil $R \$ 2,68 / \mathrm{m}^{3}$. Quanto às tarifas médias cobradas, a região Sul assume a primeira colocação com a tarifa mais cara do país $\left(R \$ 3,40 / \mathrm{m}^{3}\right)$, porém, a tarifa média paranaense é de $\mathrm{R} \$ 2,72 / \mathrm{m}^{3}$ que não alcança nem a tarifa média nacional que é de $\mathrm{R} \$ 2,75 / \mathrm{m}^{3}$ (BRASIL, 2016b, p. 54-55). Quanto aos valores cobrados pela tarifa média paranaense, estes se mostram economicamente interessantes aos usuários quando comparados aos outros estados da região Sul do país.

Infelizmente, o estudo acerca das economias residenciais contempladas com tarifa mínima ou social paranaenses (Sanepar) apresentou índices incoerentes, pois especificamente neste caso, o somatório do número de economias residenciais micromedidas contempladas com a tarifa mínima e o número de economias residenciais contempladas com a tarifa social ultrapassam a quantidade de economias residenciais ativas de água, totalizando um percentual de 106,5\%. O próprio estudo reconhece que estes números indicam um possível problema na informação prestada (BRASIL, 2016b, p. 79-81). Estes valores seriam fundamentais para fornecer um panorama real sobre a utilização da tarifa mínima de consumo no estado do Paraná.

De acordo com este cenário exposto, a estrutura tarifária mais frequente no país é a de volume de $10 \mathrm{~m}^{3}$ como a primeira faixa de consumo, porém, essa faixa de cobrança tende a prejudicar quem consome menos. Assim, aqueles que consomem menos que os volumes estipulados passam a pagar um valor maior pelo metro cúbico de água, desincentivando o uso racional desse insumo. Não se ignora que a empresa concessionária precise cobrir seus custos de serviço, porém, a atual estrutura acaba por beneficiar aqueles que consomem mais.

As tarifas devem ser capazes de manter o equilíbrio econômico e financeiro do prestador de serviços, bem como a modicidade das tarifas, fazendo uso de mecanismos capazes de induzir a eficiência e a eficácia do serviço prestado, além de permitir a universalização dos serviços de água e esgotos. Aliado a isso, o cenário variável por todo o território brasileiro demonstra que este equilíbrio e a modicidade da tarifa é um resultado difícil de estabelecer e, além disso, há o compromisso ambiental em racionar a água como recurso escasso. 


\section{A TARIFAÇÃO MÍNIMA A PARTIR DA LEI N. 13.312/2016 SOB A PERSPECTIVA DA ANÁLISE ECONÔMICA DO DIREITO}

A tarifa mínima de água é prática comum no país há pelo menos quatro décadas, envolta pelas mais diversas legislações federais e estaduais. Assim, as companhias de saneamento possuem certa liberdade ao fixar tais parâmetros e não se mostram embasadas em quaisquer estudos técnicos ou científicos que justifiquem tais fixações. E ainda que o fizesse há décadas atrás, esse valor não se mostrou alterado por diversos estados brasileiros até os dias atuais.

O que se questiona, neste caso, é a viabilidade de sua manutenção em face de uma realidade completamente diferente àquela onde fora fixada. É certo que padrões, e principalmente as preocupações ambientais, tornaram-se mais objetivas, realistas e manifestamente urgentes no âmbito nacional e global. Consequentemente, essa tarifação merece, ao menos, ser observada sob uma nova ótica que possa trazer opções ambientais que também sejam racionais. É neste cenário que se insere a Análise Econômica do Direito (AED) e, fazendo uso de seus conceitos, analisar se esta tarifação mínima de água merece ser revisitada.

Um primeiro ponto que merece ser esclarecido é que a noção de escassez, para a Economia, não está relacionada necessariamente à ideia de raridade de um recurso, mas sim com a oferta ou disponibilidade limitada de um bem considerado necessário na sobrevivência do ser humano. Com tais bens, o homem satisfaz suas necessidades.

Porém, ainda com a flexibilização trazida pelo desenvolvimento tecnológico, a limitação ao estoque de recursos naturais é insuperável e incontornável nas condições atuais. Assim, segundo Carneiro (2003, p. 60) está-se "diante da chamada 'Lei da Escassez', o problema econômico básico de qualquer sociedade se assenta no 'que e em que quantidade produzir os bens necessários', no 'como produzir esses bens' e no 'para quem são produzidos tais bens'”.

Ainda que seja utilizada como argumento para a defesa da propriedade privada, neste ponto merece trazer ao estudo a "tragédia dos comuns" ${ }^{10}$ como "uma metáfora utilizada para representar a inevitável 'infelicidade' da condição humana diante do descompasso entre suas necessidades ilimitadas e os limitados recursos disponíveis no planeta" que "busca associar a ideia simbólica de 'tragédia' às consequências negativas advindas do processo de crescimento populacional" (AGUSTINHO, 2011, p. 49-50).

\footnotetext{
${ }^{10}$ Originalmente, do artigo the Tragedy of the Commons, de Garrett Hardin, 1968.
} 
Na interpretação de Agustinho (2011, p. 50-51), o desequilíbrio entre as necessidades humanas e os recursos naturais disponíveis, representando uma tragédia, para ser resolvido, demanda uma mudança dos valores que orientam a humanidade atualmente, principalmente no que tange a liberdade individual:

Esta então é a tragédia. Todo ser humano busca individualmente a maximização da sua utilidade de forma infinita em um mundo cujos bens são finitos. Desse modo, o exercício dessa liberdade, ao invés de representar o resultado positivo racionalmente esperado por cada um isoladamente, conduz à sobreutilizaçao e ao esgotamento dos recursos naturais. (AGUSTINHO, 2011, p. 52).

Para Cooter e Ulen (2010, p. 25-26), a Economia forneceu uma teoria científica capaz de prever os efeitos das sanções legais sobre o comportamento e assim, para os economistas, "as sanções se assemelham aos preços, e, presumivelmente, as pessoas reagem às sanções, em grande parte, da mesma maneira que reagem aos preços", ou seja, quando os preços se elevam, as pessoas consomem menos do produto que se tornou mais caro. Dessa forma, a Economia é capaz de fornecer uma teoria comportamental de previsão da reação dos indivíduos aos comandos legislativos e essa teoria fundada na reação das pessoas a incentivos supera a intuição, fazendo da Economia a parte da ciência comportamental mais útil para o direito.

Além de uma teoria científica do comportamento, a Economia estabelece padrões normativos úteis para se avaliar o direito e as políticas públicas, ou seja, ela é capaz de prever os efeitos destas políticas públicas sobre a eficiência. A eficiência, por sua vez, é fundamental nos objetivos de qualquer política pública, dado que custos menores são os mais importantes para o Estado em sua consecução (COOTER; ULEN, 2010, p. 26).

Porém, merece observância, segundo Cooter e Ulen (2010, p. 26), a "eficiência social", pois um bom sistema jurídico deve manter alinhados a eficiência e o bem-estar da população, de maneira que aquele que busca a eficiência também vislumbre trazer benefícios ao público.

Fundado nisso, mostra-se a pertinência do argumento econômico já anteriormente exposto constante no parecer positivo da Comissão de Desenvolvimento Regional e Turismo à Lei n. 13.312/2016 como contributiva no combate ao desperdício. Ainda, o parecer argumenta que "sob o prisma econômico, a medida [a adoção do hidrômetro individual] coíbe o chamado comportamento de 'carona', que ocorre quando um indivíduo usufrui de um bem comum em medida maior do que a de sua contribuição para o custeio desse mesmo bem" (BRASIL, 2012, p. 03). 
Portanto, a adoção do hidrômetro individual não vai, por si só, contribuir para um processo de economia do consumo de água eficiente. Embora seja possível reconhecer que a medida tende a desestimular o consumo desenfreado porque agora o pagamento do consumo não será mais rateado e sim individualizado, de outro é possível também verificar que a sua adoção sem o fim da tarifa mínima continuará a gerar desperdício, na medida em que a sua fixação tende a elevar o padrão de consumo até o limite daquele teto fixado na política pública.

Cooter e Ulen (2010, p. 120-121) explicam que, quando se trata de bens privados, a eficiência exige que estes sejam de propriedade privada e como implicam rivalidade e exclusão, precisam ser controlados por pessoas ou pequenos grupos de pessoas. Porém, quando se trata de bens públicos (de propriedade pública), estes bens não implicam rivalidade ou exclusão, podendo ser controlados por um grande grupo de pessoas, como é o caso do Estado. Assim, o caráter técnico destes últimos bens acaba obstruindo o uso da negociação como forma de alcançar a eficiência e é neste ponto que a figura do caronista compromete a eficiência.

De fato, as pessoas que não pagam pelo consumo de um bem público e que são chamadas de caroneiras ou free riders (COOTER; ULEN, 2010, p. 121), podem ser identificadas na relação existente entre moradores de um condomínio residencial que representam apenas um usuário frente à companhia de saneamento.

O caroneiro pode ser representado por uma família inteira (que responde apenas por uma cota, um imóvel, assim como responde um morador que reside sozinho) que se sente incentivada a desperdiçar água (banhos longos, vazamentos sem manutenção, torneiras abertas, etc.), uma vez que seu consumo maior não implicará em um aumento equivalente em sua conta final, pois o rateio normalmente acontece em quotas iguais para cada imóvel, embora alguns condomínios residenciais se utilizem do sistema de rateio por número de indivíduos residentes e não pelo número de imóveis.

Este indivíduo/família passa a valer-se do sucesso de um empreendimento e usufrui de um bem além daquilo pelo qual custeia. Com as previsões da Lei n. 13.312/2016 essa situação cessa e o caronista é "incentivado" a economizar este bem, além de custear o consumo real que realiza. Dessa forma, promove-se a adequada alocação deste recurso escasso. Neste ponto, a Lei é capaz de combater esta figura oportunista, uma vez que, na situação anterior o indivíduo não economiza o recurso, pois não tem certeza que outro com o qual rateia quotas, também o faz. Consequentemente, os atributos comportamentais destes agentes humanos unidos pelas condições de racionalidade limitada e oportunismo explicam este tipo de comportamento (WILLIAMSON, 1985, p. 29). 
Há que se pensar que, observando este cenário oportunista em que os agentes atuam na tentativa de obterem maiores vantagens quando comparadas àquelas pelas quais arcaram efetivamente, é incompreensível a inutilização da racionalidade como requisito de escolha para uma atuação cooperativa entre os players. Considerando que a cooperação demanda uma importância no futuro quando comparada a existente no presente, uma vez que se o futuro não for importante, a cooperação provavelmente não será estável, os agentes/usuários do recurso (água) tenderiam a economizar, por si só, o uso de água, contando com o comportamento cooperativo no mesmo sentido do outro player (KOLLER; RIBEIRO, 2015, p. 38-39).

Aumentar a importância no futuro em relação ao presente, juntamente com a alteração das recompensas dos jogadores e ensinar as pessoas a se importarem umas com as outras, ou seja, ensinar aos jogadores valores, são, segundo Axelrod (2010, p. 117-132) as categorias necessárias a serem consideradas para a promoção da cooperação mútua por meio de mudanças na própria situação estratégica.

Em um cenário de rateio de água condominial, uma vez que já é nítida a importância no futuro por tratar-se de uma relação contínua, resta, principalmente, a medida que seria mais efetiva: alterar a recompensa dos jogadores, ou seja, incentivá-los financeiramente a economizar no consumo, o que só faria sentido para aqueles que se localizam na faixa dos $10 \mathrm{~m}^{3}$ saírem de uma faixa estagnada e pagarem pelo consumo efetivo, e não pelo consumo presumido da categoria. Quando enquadrados nesta categoria, os jogadores não são recompensados se cooperarem e sentem-se desestimulados a fazerem.

Porém, o que se observa nas condições atuais de consumo de água em condomínios residenciais rateados (sem hidrômetros individuais) é uma consciência distorcida generalizada de que não irá economizar no consumo, pois se pressupõe que o "vizinho" também não o fará, constituindo o denominado, pelos economistas, de "risco moral" ou moral hazard (OZELAME, 2016, p. 85-89).

Embora o risco moral seja amplamente discutido nos eventos segurados, isso não impede, por tratar-se nada mais que um exemplo de comportamento oportunista, de identificalo no objeto deste estudo. Em razão do risco moral, a companhia de saneamento dilui seus efeitos aumentando os custos dos demais usuários que arcam com a indiferença no comportamento oportunista do agente que acaba, por sua vez, atingindo o bem-estar de terceiros (assumindo a posição de falha de mercado como externalidade, neste caso) (MACKAAY; ROUSSEAU, 2015, p. 138-142). 
Ainda que em um cenário propício e vantajoso para a atuação cooperativa (onde economizar individualmente levaria a um cenário de economia comum se todos os jogadores agissem no mesmo sentido), os usuários de água assim não o fazem em um evidente desconhecimento de valores capazes de conduzir a cooperação vantajosa para todos. Estes jogadores assumem o risco de o evento menos vantajoso ocorrer (todos os usuários sobreutilizarem o bem) e pagar um valor superior àquele realmente devido em prol de uma situação mais provável e mais vantajosa para ele: outros usuários consumirem menos e arcarem com parcela de seu consumo rateado igualmente.

Parece mesmo ser uma incoerência a atuação oportunista no caso em estudo, mas em caráter de exceção, ainda existirão aqueles que, agindo como um free rider, tiram proveito da situação valendo-se apenas da economia feita pelo outro, deixando de compreender que se a economia do outro somasse a sua própria, o montante economizado, e por consequência, o valor total rateado, seria ainda mais vantajoso para ambos. É nesse sentido que North (2010, p. 25) explica que:

A teoria dos jogos caracteriza o problema. As pessoas geralmente acham que vale a pena cooperar com as outras nas trocas quando o jogo é repetido, quando possuem informações completas sobre o desempenho passado do outro jogador e quando há um número pequeno de jogadores. É difícil de sustentar a cooperação quando o jogo não se repete (ou é finito), quando falta informação sobre os outros jogadores e quando há um grande número de jogadores.

A teoria dos jogos que auxilia na compreensão do processo de decisão dos agentes que interagem, traz apontamentos importantes sobre a capacidade dos jogadores em raciocinar estrategicamente e este comportamento estratégico envolve o conhecimento por um jogador de que suas decisões afetam as decisões dos outros jogadores e assim, vice-versa, tornando-se um pressuposto fundamental, juntamente com a racionalidade, para a validade da teoria dos jogos (BECUE, 2011, p. 111-113).

A partir destes apontamentos e de acordo com Ribeiro (2011, p. 66), o acesso às informações para que a cooperação se efetive é de fundamental importância, pois as assimetrias informacionais como uma falha de racionalidade dos agentes impactam decisivamente na formação de suas vontades e conduzem a um comportamento oportunista, justamente o que se pretende combater, conforme justificado pelo Projeto de Lei que deu origem a Lei n. 13.312/2016. Dessa forma, a desonestidade oportunista de certos agentes acaba por implicar em custos gerais quando não inibida de maneira eficiente (TOKARS, 2011, p. 94). 
Por fim, mesmo diante de aspectos da AED, os usuários que se enquadram na categoria de tarifa mínima de água, encontram-se em uma espécie de "limbo", pois, mesmo diante das novas previsões da Lei n. 13.312/2016, são esquecidos ou desestimulados a atuarem como agentes cooperativos.

\section{CONSIDERAÇÕES FINAIS}

Mediante o que se observa a partir do estudo, a tarifa mínima de água fixada em 10m³, por exemplo, para o estado do Paraná, não provém de uma decisão técnico-econômica recente. Na verdade, já na década de setenta, pode-se encontrar legislações que previam tal tarifação. Transcorridas pelo menos quatro décadas e esta categoria preestabelecida de consumo mínimo mantém-se inalterada pela maioria dos estados brasileiros.

Considerando a atual realidade ambiental com a adoção de medidas mais efetivas no combate à degradação (muito distante daquela consciência utópica ambiental de preservação a todo custo ou, no caso do Brasil, de desenvolvimento a todo custo), parece ser essencial que esta categorização seja revisitada e reestudada a fim de analisar a viabilidade ambiental e econômica em mantê-la ou estudar quais seriam as alterações mais eficientes para o sistema de fornecimento de água brasileiro, considerando as especificidades de cada estado, uma vez que os custos em cada um deles divergem consideravelmente.

De acordo com a análise populacional exposta, é evidente que as família brasileiras "encolheram", ou seja, ao longo das décadas o seu número de membros tem diminuído e, aliado a isto, parcela expressiva deles passa grande parte de seu dia em ambiente diferente de sua residência.

Estes dois fatores somados impactam significativamente no consumo de água per capita residencial. Ainda que esta nova realidade seja observada facilmente, a tarifa mínima de água permanece estanque há décadas! Ainda que o número de membros em uma família diminua e seu consumo individual também, não há qualquer acompanhamento legislativo que incentive qualquer família a economizar, pois estão obrigatoriamente atreladas a uma categoria completamente destoante da realidade.

Diante deste ineficiente cenário de consumo/cobrança e desestímulo ambiental, o que gera preocupação é que isto se intensificará com a Lei n.o 13.312/2016, pois o número de famílias afetadas, como aquelas descritas pelo IBGE, aumentará no momento em que estiverem sujeitas a tarifa mínima de água. Antes a preocupação era em economizar no consumo de água e combater o individuo/família caronista; agora cada unidade de imóvel com seu próprio 
hidrômetro individual perde essa possibilidade, pois passa a ser enquadrado, automaticamente, em sua grande maioria, dentro da faixa de consumo mínimo, ainda que não o consuma efetivamente. Assim, a referida Lei passará a sobrecarregar uma classe expressiva da população.

Em respeito às peculiaridades da população brasileira e de cada um de seus estados, uma vez que se trata de um bem essencial à sobrevivência humana, novos estudos técnicocientíficos deveriam reavaliar esta nova realidade e propor novas medidas que de fato, efetivem e incentivem a economia no consumo, especificamente quanto a esta classe que se insere no consumo de $10 \mathrm{~m}^{3}$, como, talvez, por exemplo, repensar estas categorias e sua eficiência ambiental, pois, antes disso, o serviço público não deve ser instrumento de captação de recursos, mas sim o propulsor do desenvolvimento a partir de políticas eficientes.

O próprio Projeto de Lei que deu origem à Lei n.o 13.312/2016 menciona que se deve incentivar comportamentos mais comedidos no que diz respeito à utilização dos recursos hídricos, mas em nenhum momento esta categoria estanque de consumo mínimo é mencionada ou tem suas características analisadas com profundidade.

O Projeto questiona ainda a prática atual de inclusão do consumo hídrico nas despesas condominiais partilhadas indistintamente na proporção de frações ideais e chama de inadequado e injusto este modelo que parece direcionado a prejudicar aqueles mais conscientemente econômicos, ensejando em elevado desperdício.

A AED não discorda deste evidente comportamento oportunista e de seus resultados negativos para uma atuação cooperativa, assim como foi objeto de pertinente análise no parecer da Comissão de Desenvolvimento favorável à Lei. Porém, mais uma vez questiona-se a categoria ignorada pelo Projeto de Lei e sua respectiva Lei, nas quais todas as justificativas plausíveis e louváveis não houve qualquer menção à tarifa mínima de água. Um problema complexo como o crescente risco de escassez deste recurso natural deve ser minuciosamente analisado e demanda diversas frentes de combate.

Neste ambiente (anterior à Lei n. 13.312/2016) propício à cooperação, ainda assim os usuários não agem da maneira mais racional e o que se questiona é se a introdução do hidrômetro individual seria a solução mais eficiente, pois intensifica a problemática daqueles que se enquadram no consumo mínimo, ou se estimular práticas que conduzam a atuação cooperativa produziria resultados mais duradouros e eficientes, por meio da difusão dos valores da cooperação, principalmente alterar as recompensas dos jogadores para que estas sejam interessantes aos players em manter-se no jogo e cooperando a cada rodada. 
Por óbvio que a preocupação em estimular um comportamento ambiental racional de economia no consumo de água é essencial nas condições atuais em que se encontram o planeta, mas o que este estudo pretende destacar é que em nenhum momento há menção a grande parcela da população que hoje se encontra na categoria de consumo mínimo e que permanece inalterada e desconsiderada pela Lei n. 13.312/2016.

Não se questiona que o escalonamento da tarifa é justo e viabiliza que aqueles que consomem mais arquem com valores maiores. Porém, considera-se que as faixas não devem ser demasiadamente longas ou curtas demais. Neste sentido, necessário se faz uma ampla discussão a fim de adequar o sistema de cobrança de maneira que ele valorize as unidades que utilizam água de forma racional e desestimule o uso indiscriminado do recurso, efetivando o direito universal ao uso da água ao mesmo tempo em que torna viável economicamente o serviço de água prestado pela empresa de abastecimento.

Assim, faz-se a sugestão de que sejam elaborados novos estudos técnicos e científicos a fim de analisar a viabilidade econômico-financeira de uma nova categoria de tarifa mínima de água como, por exemplo, 5 ou $6 \mathrm{~m}^{3}$ ou qualquer outro número que seja condizente com o consumo consciente e capaz de incentivar o uso deste recurso natural sem comprometer 0 desenvolvimento.

Por fim, a educação assume o papel de destaque como medidas de incentivo ao consumo consciente e pode ser vista como a solução mais eficiente, todavia, produz efeitos sólidos apenas no longo prazo e, dada a urgência da questão em níveis globais, nacionais e regionais, fundamental se faz a necessidade de que medidas mais efetivas sejam implementadas imediatamente.

O consumidor precisa entender que qualquer medida estatal que não seja acompanhada por uma mudança em seus próprios hábitos, é inócua e o Estado precisa, em suas políticas de tarifação, buscar um equilíbrio entre os objetivos econômicos, ambientais e sociais, proporcionando uma alocação ótima dos recursos hídricos.

\section{REFERÊNCIAS}

AGUSTINHO, Eduardo Oliveira. As tragédias dos comuns e dos anticomuns. In.: RIBEIRO, Marcia Carla Pereira; KLEIN, Vinícius (coords.). O que é análise econômica do direito: uma introdução. Belo Horizonte: Fórum, 2011.

AXELROD, Robert. A evolução da cooperação. Tradução de Jusella Santos. São Paulo: Leopardo Editora, 2010. 
BECUE, Sabrina Maria Fadel. Teoria dos jogos. In.: RIBEIRO, Marcia Carla Pereira; KLEIN, Vinícius (coords.). O que é análise econômica do direito: uma introdução. Belo Horizonte: Fórum, 2011.

BETTI JR., Leonel. Análise econômica do direito à informação para o consumo e a construção de um modelo de desenvolvimento sustentável. In.: MEIRELLES, Jussara Maria Leal de; RIBEIRO, Marcia Carla Pereira. Direito e desenvolvimento: biomedicina, tecnologia e sociedade globalizada. Belo Horizonte: Fórum, 2011.

BLANCHET, Luiz Alberto. Energia elétrica e desenvolvimento: os custos, a tarifa e suas suscetibilidades e impactos na vida do cidadão. In.: GONÇALVES, Oksandro; HACHEM, Daniel Wunder; SANTANO, Ana Claudia. Desenvolvimento e sustentabilidade. Curitiba: Ithala, 2015.

Direito da energia: economia, regulação e sustentabilidade. Curitiba: Juruá, 2014.

Direito Administrativo: o Estado, o particular e o desenvolvimento sustentável. Curitiba, Juruá, 2011.

Concessão de serviços públicos. 2. ed. Curitiba: Juruá, 2006.

BRASIL. Lei n.o 13.312, de 12 de julho de 2016. Diário Oficial, Brasília, DF, 12 jul. 2016 (ed. extra). 2016a. Disponível em: <https://www.planalto.gov.br/ccivil_03/_ato20152018/2016/lei/l13312.htm>. Acesso em: 04 nov. 2016.

Ministério das Cidades. Secretaria Nacional de Saneamento Ambiental. Sistema Nacional de Informações sobre Saneamento. Diagnóstico dos serviços de água e esgotos - 2014. Brasília: SNSA/MCIDADES, 2016b. Disponível em: <http://www.snis.gov.br/diagnostico-agua-eesgotos/diagnostico-ae-2014>. Acesso em: 14 nov. 2016.

Senado. Parecer da Comissão de Desenvolvimento Regional e Turismo, sobre o Projeto de Lei do Senado no 444, de 2011, do Senador Antonio Carlos Valadares. 2012. Disponível em: $<$ http://www.senado.leg.br/atividade/rotinas/materia/getPDF.asp?t=114148\&tp=1>. Acesso em: 04 nov. 2016.

Senado. Projeto de Lei n.․ 444, de 03 de agosto de 2011. Altera a Lei no 11.445, de 05 de janeiro de 2007, que estabelece diretrizes nacionais para o saneamento básico e dá outras providências, para determinar a medição individualizada do consumo hídrico nas edificações condominiais. 2011. Disponível em: <http://legis.senado.leg.br/mateweb/arquivos/matepdf/93944.pdf>. Acesso em: 04 nov. 2016.

Decreto n. 7.217, de 21 junho de 2010. Diário Oficial, Brasília, DF, 22 jun. 2010 (ed. extra). 2010a. Disponível em: <http://www.planalto.gov.br/ccivil_03/_ato20072010/2010/Decreto/D7217.htm>. Acesso em: 01 nov. 2016.

Superior Tribunal de Justiça. Acórdão. Recurso Especial n. 1166561/RJ. Primeira Seção. Relator Min. Hamilton Carvalhido. Recorrente: Companhia Estadual de Águas e Esgotos CEDAE. Recorrido: Centro Profissional José de Miranda Sá Sobral - Galeria Central de Nilópolis. DJe, Brasília, 05 out. 2010. 2010b. Disponível em: <https://ww2.stj.jus.br/processo/revista/documento/mediado/?componente=ITA\&sequencial= 996747\&num_registro=200902249984\&data $=20101005 \&$ formato=PDF>. Acesso em: 01 nov. 2016.

Lei n.o 11.445, de 05 de janeiro de 2007. Diário Oficial, Brasília, DF, 11 jan. 2007. 2007. Disponível em: <http://www.planalto.gov.br/ccivil_03/_ato2007-2010/2007/Lei/L11445.htm>. Acesso em: 01 nov. 2016.

Lei n.o 9.433, de 08 de janeiro de 1997. Diário Oficial, Brasília, DF, 09 jan. 1997. 1997. Disponível em: <http://www.planalto.gov.br/ccivil_03/leis/L9433.htm>. Acesso em: 05 nov. 2016.

Ministério do Planejamento e Orçamento. Instituto de Pesquisa Econômica Aplicada. Texto para discussão no 415: estudo da função demanda por serviços de saneamento e estudo 
da tarifação do consumo residencial. Rio de Janeiro; Brasília: IPEA, maio 1996. 1996. Disponível em: <http://repositorio.ipea.gov.br/bitstream/11058/1788/1/td_0415.pdf>. Acesso em: 09 nov. 2016.

Lei n.o 8.987, de 13 de fevereiro de 1995. Diário Oficial, Brasília, DF, 14 fev. 1995. 1995. Disponível em: <https://www.planalto.gov.br/ccivil_03/Leis/L8987compilada.htm>. Acesso em: 01 nov. 2016.

Constituição da República Federativa do Brasil de 1988. Promulgada em 05 de outubro de 1988. Diário Oficial da República Federativa do Brasil, Brasília, DF, 05 out. 1988. 1988. Disponível em: <http://www.planalto.gov.br/ccivil_03/Constituicao/Constituicao.htm>. Acesso em: 01 nov. 2016.

CARNEIRO, Ricardo. Direito ambiental: uma abordagem econômica. Rio de Janeiro: Forense, 2003.

COOTER, Robert; ULEN, Thomas. Direito \& economia. Tradução de Luis Marcos Sander e Francis Araújo da Costa. 5. ed. Porto Alegre: Bookman, 2010.

FREITAS, Vladimir Passos de. Águas - considerações gerais. In.: FREITAS, Vladimir Passos de. (coord.). Águas: aspectos jurídicos e ambientais. 2. ed. Curitiba: Juruá, 2002.

GRANZIERA, Maria Luiza Machado. Direito de águas: disciplina jurídica das águas doces. 3. ed. rev. atual. São Paulo: Atlas, 2006.

HARDIN, Garrett. The tragedy of the commons. Science, v. 162, Issue 3859, p. 1243-1248, 13 dec. 1968. Disponível em: <http://science.sciencemag.org/content/162/3859/1243.full>. Acesso em: 21 nov. 2016.

INSTITUTO BRASILEIRO DE GEOGRAFIA E ESTATÍSTICA. Pesquisa nacional por amostra de domicílio. Síntese de indicadores 2012. 2012. Disponível em: <http://www.ibge.gov.br/home/estatistica/populacao/trabalhoerendimento/pnad2012/sintese _defaultpdf_familias.shtm>. Acesso em: 22 nov. 2016.

KOLLER, Carlos Eduardo; RIBEIRO, Marcia Carla Pereira. Racionalidade econômica e a negociação coletiva de trabalho. Revista de Direito Empresarial, Belo Horizonte, a. 12, n. 2, p.3350, maio/ago. 2015.

MACKAAY, Ejan; ROUSSEAU, Stéphane. Análise econômica do direito. Tradução de Rachel Sztajn. 2. ed. São Paulo: Atlas, 2015.

MELLO, Celso Antônio Bandeira de. Curso de Direito Administrativo. 32. ed. rev. e atual. São Paulo: Malheiros, 2015.

NORTH, Douglass C. Desempenho econômico através do tempo. Tradução de Antonio José Maristello Porto. Revista de Direito Administrativo, Rio de Janeiro, v. 255, p. 13-30, set./dez. 2010.

em: <http://bibliotecadigital.fgv.br/ojs/index.php/rda/article/view/8428/7177>. Acesso em: 16 nov. 2016. 
OZELAME, Rafael Henrique. Contrato de seguro e risco moral. In.: RIBEIRO, Marcia Carla Pereira; DOMINGUES, Victor Hugo; KLEIN, Vinicius. Análise econômica do direito: justiça e desenvolvimento. Curitiba: CRV, 2016.

PARANÁ. Decreto Estadual n.o 3.576, de 29 de fevereiro de 2016. Diário Oficial, Curitiba, PR, 01 mar. 2016.2016 .2 Disponível em: <http://www.legislacao.pr.gov.br/legislacao/listarAtosAno.do?action=exibir\&codAto=153117\&i ndice $=1 \&$ totalRegistros $=161 \&$ anoSpan $=2016 \&$ anoSelecionado=2016\&mesSelecionado=2\&isPag inado=true $>$. Acesso em: 14 nov. 2016.

RIBEIRO, Marcia Carla Pereira. Racionalidade limitada. In.: RIBEIRO, Marcia Carla Pereira; KLEIN, Vinícius (coords.). O que é análise econômica do direito: uma introdução. Belo Horizonte: Fórum, 2011.

SEN, Amartya Kumar. Desenvolvimento como liberdade. São Paulo: Companhia das Letras, 2000.

TOKARS, Fabio Leandro. Assimetria informacional. In.: RIBEIRO, Marcia Carla Pereira; KLEIN, Vinícius (coords.). O que é análise econômica do direito: uma introdução. Belo Horizonte: Fórum, 2011.

WILLIAMSON, Oliver E. The economic institutions of capitalism: firms, markets, relational contracting. New York: The Free Press, 1985.

TRABALHO ENVIADO EM 11 DE JUNHO DE 2017.

ACEITO EM 07 DE SETEMBRO DE 2017. 